\title{
Strategies for Overcoming Fear to Become an Elegant Presenter
}

\section{Reaz Hafiz}

Lecturer, School of Business Studies, Southeast University, Dhaka, BANGLADESH

*Corresponding Contact:

Email: rocking_reaz@yahoo.com

Cell Phone: +8801614336620

\begin{abstract}
Communicating an effective message by focusing on useful content is crucial for perfect presentation. Confirmation of the message construction is possible only by proper planning and doing perfect research on the stipulated topic. The presentation goal is to communicate the required message in an understandable medium to the target audience. As verbal and nonverbal factors carry the same weight, considering them equally to develop strong presentation skills are mandatory. Therefore the main concentration of the paper is on the strategies required to know to get the proper preparation for presentation to overcome fundamental problems. The importance of relevant ground work on preparing presentation, the way to use phrasing, pausing, the techniques of writing a speech, use of visual aids all the fields are included in the paper to make a presenter elegant.
\end{abstract}

Keywords: Presentation, Strategies for Good Presentation, Speech Writing, Visual Aid, Oral Presentation.

JEL Classification Code: M00

$8 / 27 / 2015$

Source of Support: Nil, No Conflict of Interest: Declared

How to Cite: Hafiz R. 2015. Strategies for Overcoming Fear to Become an Elegant Presenter ABC Journal of Advanced Research, 4, 91-98.

This article is is licensed under a Creative Commons Attribution-NonCommercial 4.0 International License. Attribution-NonCommercial (CC BY-NC) license lets others remix, tweak, and build upon work non-commercially, and although the new works must also acknowledge \& be non-commercial.

\section{INTRODUCTION}

"Fear" - the first word comes to the mind of most of the students when they are assigned to any kind of presentation task. However in today's competitive world, strong communication and presentation competencies are must need for getting success. Turn out employable graduates has become an essential criterion in higher education (Raybould \& Sheedy, 2005). Presentation is related with every steps of life. Sometime it is very formal and creates an edgy state when it is related with any kind of expectation. The mode of return can be explained in monetary terms if it is related with business and can be in numbers if it is the part of study. Therefore students cannot avoid public speaking by any chance. Teachers are now focusing on the way to develop this extraordinary skill. In some courses, extra numbers are assigned to presentation. Some schools have the required courses related to communication that incorporate presentations and reports as well as seminars into standard class activity. As noted by Parvis (2001), to speak effectively in 
front of a group is a skill that has to be taught to students and needs to be honed throughout college life and into the job market (p. 44).

\section{OBjectives}

Most of the students have fundamental problems that lead them toward frustration presentation not only in the business field but also in other academic disciplines as well. Therefore the key focus point of the paper is on the strategies required to know to get the proper preparation for presentation to overcome those fundamental problems. So the paper is going to address five essential tasks of a presenter: (1) Relevant ground work on presentation (2) Techniques to write speech for delivery (3) Significance of phrasing, blending \& pausing in speech (4) Proper tactics of using visual aids (5) Methods of doing practices.

\section{SigNificANCE OF THE STUdY}

Presentation is a skill that is required to be developed with the pace of time. As Students come from different cultural and educational backgrounds, their learning curves are not same. So with the proper guidance they can develop the communication skills. There are many possibilities to develop presentation skills of students of colleges and universities (Gallo, 2006). In this paper, the author has tried to emphasis on the necessary components of presentation preparation systematically so that students can understand them easily and by following them, they can present a topic with greater acceptance. The importance of doing ground work before presentation, the way to use phrasing, pausing, the techniques of writing a speech, use of visual aids all the fields are included. So it will be easier for a presenter to understand the proper way to prepare them for presentation in every aspect of life.

\section{Methodology}

The nature of the study is exploratory. In the study, the author collected data from secondary sources such as various journals, publications, research works, books and websites. The study is absolutely concentrated towards the field of presentation skill development strategies. All the references are given in the end part of this paper.

\section{LITERATURE REVIEW}

As technological advancement has taken different forms, people have started to use them in their daily presentation. However, many of the old problems are not resolved yet such as inappropriate usage of grammar and mechanics, (Sheets, 2004; McCannon and Crews, 1999); inadequate planning and organizing in case of writing different formal report (Strunk and White, 1959; Dauwalder, 2000; Scott, 2001), and poor skill in oral presentation (Bippus and Daly, 1999; Hoff and Tian, 2005).

Because of the above mentioned problems, when a student is going to present anything, he or she faces an anxiety that is related with communication known as oral communication apprehension. According to McCroskey (1977) "an individual's level of fear or anxiety associated with either real or anticipated communication with another person or persons" (p.78). McCroskey also expressed that the basic components of oral communication anxiety are learned helplessness and learned negative expectations (Seligman, 1975). This two things work together negatively to increase anxiety and the result is low confidence that ultimately affect one's action in the time of delivery. 
Even in the twenty-first century, nervousness in the time of public speaking is a big problem. Krannich (2004) stated that the fear of communication or presentation is the number one fear among most people, including students and adults from different backgrounds. According to krannich (2004), the promoted individuals in an organization require to deliver a speech to peers upon his acceptance of the new post. Because of fear of oral communication, some individuals not even take the advantage of accepting a higher position in an organization.

Philips (1968) mentioned that, some factors regarding poor communication performance might lie in one's memory from his childhood because of family and surroundings such as verbal harassment by family members, rebuking one another in the society or misusing of language publicly by parents in the time of criticism. As the child become adult, the negative experiences may lead him or her to become fearful at the period of encountering oral communication.

Appropriate guideline and proper training can reduce one's apprehension of oral presentation as the author has already mentioned that fear of participating in oral communication activities is learned or reinforced by experience.Therefore in this paper, the author has tried to find out the best way of preparing oneself for any kind of presentation in order to increase confidence and to overcome fear whenever one needs to present in public.

\section{Ground Work on Preparing Presentation}

Before presenting any topic the first task of a presenter is to know it precisely. If a driver drives his car on the road without knowing the rules, he or she must have to face difficulties. So if a presenter goes to deliver his speech in front of audiences without doing proper ground work, difficulties may arise along with lack of confidence. So doing essential ground works are unavoidable.

\section{Scrutinizing the Condition:}

Topic selection can be easier if the background is clear. It can help one to make the topic much more interesting to the audience at the time of delivery though it is not an easy task. In many of the educational circumstances, students have a very poor knowledge about the topic because they only prepare themselves for the portion they are going to present without having any idea about the total subject. Overall knowledge about the subject is mandatory. Beside this, audiences love to hear speech when they can make a connection among the delivered materials. Synchronization among delivered speech can make the presentation more attention-grabbing.

It is necessary to know the allocated time for the total presentation. The distribution of time according to the importance of the topic is much easier then. The number of audiences can also affect the presentation. If the audience is large enough, one may use different visual aids as well as control the delivery of speech along with the smart use of dais. If the audience is small in number, the delivery style should be environment-friendly.

\section{Topic Selection:}

A sound presentation topic can signify the difference between audience boredom and viewer admiration. One may think that he/she has an infinite number of choices to esteem the audience, but before selecting a topic for a speech he/she may find difficulties. Difficulties can be reduced by following number of ways:

First, one has to know the purpose of presentation in certain occasion. The purpose can be to inform, persuade or just to entertain the audience. If it is clear and relevant to the 
stipulated circumstance, many other irrelevant topics can be eliminated than before brainstorming session starts.

Secondly, in the time of brainstorming, clear idea about the nature of the audience is a must. The depth of knowledge of the audience, their education level, the area of interest and demographic conditions need to go through. This study can help to secure audience's attention and ensure their understanding along with remembrance.

Final touch point is presenter's area of passion which can recharge the audience too in the time of delivery. Excitement comes out in the face if the topic is related to the personal experience or if the presenter has a thorough knowledge about the topic. Audience can find the topic interesting if the topic is blistering one. Beside this it is very crucial to deliver the speech with clarity and confidence.

\section{Assembling Topic Related Information:}

After selecting a topic, collection of related information is an important task. Now a day, people can take the help of internet in order to gather vast information about anything they like. They may use other secondary sources too. Depending on the topic, primary source can also be used for data collection. After assembling all the information, presenter needs to organize them according to the delivery plan.

\section{Put In Order and Write the Speech}

The key to presenting a perfect speech is to organize information, then prepare it and practice it a lot. Even world leaders do not just stand up and make up a speech on the spot - they carefully prepare beforehand. A good speech carries a message which fits with the event. So it should be written with great care. Some people think that what is in the report should be presented directly. But report writing and speech writing is not the same. In case of a written report one can read it repeatedly until he or she understands the matter but in case of delivering the written speech the audience cannot turn back. Therefore, it is important to repeat often throughout the presentation. The informal formula for public speaking is - "First, give the audience a brief summary, then tell them the actual story, and then wrap up the story by repeating what they already heard."

An outline should be prepared first to make the speech attractive. The skeletal structure can easily assist to develop the total speech. A speech outline should include an introductory part, a main body of the speech and a conclusion and a few bullets for each section. Subheadings can also be incorporated if necessary.

\section{Outlining the Introduction:}

The way to introduce a speech is not same in every occasion. The introduction should capture the audience's attention. These may be done by starting with an indisputable note. Few suggestions may include: (a) A recent event can be referred (b) A real life story can be shared (c) A famous quote can be quoted (d) A question can be raised (e) A surprising statistics can be demonstrated

One can then introduce himself to the audience. However if someone else has introduced prior to the speech, then take a few moments to thank them. Then the topic should be mentioned clearly so that the audiences know what is going to be presented.

In the next step, the audience should be given with some background information about the presentation topic so that they can simply follow the delivery of the speaker. At the end part of the introduction, a statement can be used to connect the introduction part with its body 


\section{Outlining the Body:}

The key attention of the total presentation is in the body part. Here the presenter needs to come out with some points of arguments in favor of the topic. The most accommodating point should come first which will help to clutch the judgment of the audience in favor of the issue. Other points can then follow the lead. Proper quotation may make the arguments stronger. The points of disagreements should also be presented to remove the confusion of the audiences.

Real life examples can increase the confidence level of listeners, and they may find it interesting if they can understand the story clearly and recall something similar to their life.

The purpose of the speech may be to inform, educate, advocate or entertain the audiences. So the final task of the body part is to tell the audience what they should do with the information they got from the speech that has been delivered.

\section{Outlining the Conclusion:}

"Finally", "In conclusion", "One more thing", "In summary, "At the end", "Last but not the list" these types of concluding remarks can be used when the speech is in the ending part. Repeating the supporting points give the credibility to the topic.

Finally, questions can be invited about the discussed topic from the audience. After satisfying the audience the speaker can give thanks to the audience for their patience hearing and introduce the next presenter if anybody is in the queue.

\section{Phrasing, Blending, and Pausing of Speech}

Oral communication is completely different from written communication because it is more audience-specific, interactive, impulsive, personal, informal and use of visual aids. For the above causes, many things need to maintain during oral presentation. One way to uphold tempo in the speech is to break or divide the statement into breath units or thought groups which is called phrasing or oral punctuation. In the oral speech, sentences are divided into logical units that help to reinforce the meaning of the most essential parts within the sentences. Each unit contains words that belong together because of close relation and are set off from the rest by a pause. For phrasing one's speech some guidelines can be followed:

- Choice of the words should depend on the audience receptive capability. Otherwise, concentration may divert because of lack of understanding. (i.e., instead of "patience" if we use synonym like "serenity" may confuse the audience)

- Enumeration helps to tie different points together. (i.e., First, I would like to tell something about BMW. Second point would be ..........)

- Conjunctions can be used. (i.e., that, if, and, but)

- Parallel construction helps the audience to follow the topic. (i.e., Baby likes to hike, swim and ride a bicycle or Baby likes hiking, swimming or riding a bicycle.)

- Personal pronouns can be used. (i.e. I, you, he, she)

- Occasional questions can come based on situation.

Blending is the method of combining related words in order to create smooth flow of speech. It is the act of forming a phrase which can be defined as a sequence of two or more words, arranged in a grammatical construction and acting as a unit in a sentence. For example: camcorder [camera + recorder], motel [motor + hotel], modem [modulator + demodulator]. In speech, we use pause to have some positive consequence. Pausing helps us to gather our thoughts and match these to what we are delivering, or to highlight something or 
provide audience an option to absorb what we are saying. We need to pause in right place and duration of it should be précised depending on language, culture or geographic location. For easy understanding we can use rhythm pause (/) as short pause in a sentence and thought pause $(/ /)$ as long pause after a sentence. For example: Imagine / reading a book in which / there are no commas / or periods.// Page after page, / all the words run together / making it near impossible to translate / the intended meaning. / /

The use of planned pausing, proper phrasing and perfect blending of words allows one to project confidence and professionalism in delivery of a speech.

\section{The ART OF Using Visual Aids}

Output of a delivery can be more real if anyone can use visual aids flawlessly. Listeners can comprehend abstract theories when visual aids are used and let compound data to be organized and reduced to understandable and brief points. Objects, pictures, key quotes or data presented in a clear and dramatic fashion can benefit one's speech. Interest of listeners can be maintained and retained from distraction by effective visual support.

Before jumping to the different options of using visual aids, a person needs to know the principles of using them. So one should follow the following guidelines:

Using Simple Background: Presenters should use the simple background to reduce distraction. If it is cumbersome, the audience may be distracted from the focus and then the presentation may be annoying.

Font Size: Each word of every sentence should be clearly visualized from the audience chair. The font size should be large and bold enough so that the audience can go through the lines if necessary.

Complex to Simple: The background of all of the audiences is not same so as their understanding capability. In the time of presentation, presenter needs to break complex ideas into simple parts so that each person can easily understand the topic.

Communicating with Color: Proper use of color can help to shape an audience's thinking pattern and provides a precise meaning sometimes with new ideas about the delivered topic. But using too much color can make the presentation boring to the audience.

Using Images, Animations $\mathcal{E}$ Videos: Image, animation and video can make things interesting to the audience. So they can be used according to the requirement of the topic.

In the field of visual aids, many options are available. One can use the following alternatives:

White Board or Flip Chart: For developing explanation, diagrams and simple headings white board or flip chart can be used. It is very helpful during brainstorming session because audience comments can put together. But writing on a white board may take long time and clarity of handwriting is also important.

Overhead Projector: Displaying written and graphic form can be done through the overhead projector. OP is suitable for any type of audience group but sometimes it can be noisy and not reliable at all because it can obscure the screen.

Slide Show Software or Apps(i.e. Power Point, Prezi): These types of software or apps can certainly produce professional presentations. Many options are available in the updated versions that can help to make the presentation attractive. Changing anything in the slides and carrying within a disk or pen drive is very simple. 
Handouts: Summarizing the topic and including relevant points of a presentation to a handout can be a superb addition. It helps the audience to have the full records with them. However, if anyone distribute it at the beginning or middle of the presentation may distract audience attention, again distribution at the end may cause the audience to have written many unnecessary notes. One way to solve the problem is to give handouts with some incomplete parts which can be filled up by audience if necessary.

Artifacts: Using artifacts can make the subject easily understandable to the audience. In case of showing objects one has to ensure clear demonstration along with the capability of meeting audience quest in details.

\section{Practice}

Success of a perfect presentation is not only depends on knowledge, experience or talent but also on the way one is prepared for it. Practicing a speech at least once almost in a similar environment in which one is going to present with all visual aids along with the presence of audience can increase the confidence level. The following guidelines can boost the effectiveness of the time that one should invest in practice.

Location: Practice in a situation that closely mirrors the genuine presentation helps to understand the environment. It is better if anyone can go through the final rehearsal in the real place.

Voice Control: Controlling voice and changing pitch of delivery sound good. So practicing speech out loud can help to clarify different thoughts in the speech.

Do not be a Parrot or Reader: If anyone tries to memorize the whole part of presentation and attempts to deliver it accurately, it may not sound natural. Again, if anyone just goes through the visuals only by reading without any eye contact with the audience seems a boring presentation. So in the time of practicing, one should try to understand the sequence of presentation and the topic along with the use of visual aids.

Record $\mathcal{E}$ Listen: In the time of practicing it is better to record the speech and listen to the tone, pitch, speed of voice and pronunciation of words. It will help to sound and breathe naturally and decrease anxiety.

Note Clearly $\mathcal{E}$ Add Direction: Letters should be large, boldface in the script so that it is easy to follow. Because one should look up several times from script for engaging audience and would not want to lose text when look back. Beside this one can add directions like "slow down" "look at the audience" "pause" which may remind them the things they need to do during presentation.

Practice In Front of a Mirror: Rehearsing in front of a mirror can help to improve delivery style and make the decision about necessary changes.

Using Logistics: In the practice session, one should perform with all the logistics support he or she is going to use at the time of final presentation. One way it makes presenter comfortable and other way it can anticipate the possible difficulties and the way to solve those problems.

Overcoming Stage Fright: Goldman and Lehrer (1986) reported that expression of stage fright is the result of a number of independent dimensions including (1) fear of fear, (2) fear of disapproval by important others (3) problems with concentration and distraction and (4) a judgmental attitude toward problems in performance. Practicing and preparing are two best ways to eliminate stage fear. Good command in presentation topic is the first way to reduce fear. Practicing in similar place can reduce nervousness. Watching or listening to others speeches and creating mental imagery of oneself in front of audience in the practice session can increase confidence. Breathing exercise can relax nerves. In addition, if hands shake, presenter needs to hold objects like pointer or lectern.

Etiquette: Some etiquette needs to keep in mind. Such as hands movement when speaking, facial expression, formal dress sense, combination of leather of shoes and belt, not to wear heavy ornaments, shaving the face for a decent look, hairstyle should be perfect. 


\section{Concluding Remarks}

To become a good presenter, the ultimate success depends on the ultimate big event. What has been practiced should give the result at the final day. By following all the above mentioned way, one can present any kind of topic in a better way. When it is all over, feedback is necessary. It is imperative to think of that this is a learning experience which will help to become a better public speaker with the continuation of this process.

\section{REFERENCES}

Bippus, A.M. \& Daly, J.A.(1999) What do people think causes stage fright? Naïve attributions about the reasons for public speaking. Communication Education, 48, 63-72.

Daly, J.A. \& McCroskey, J.C. (1984). Avoiding Communication: Shyness, reticence, and communication apprehension. Newbury Park: Sage.

Dauwalder, D. P. (2000).Formulating sound conclusions and recommendations. The Delta Pi Epsilon Journal 42, 6-13.

Gallo, C (2006). The 10 worst presentation habits. BusinessWeek.com. Retrieved July 20, 2015, from: http://images.businessweek.com/ss/06/02/mistakes/index_01.htm

Goldman, N.S. \& Lehrer, P.M. (1986, August). Performance anxiety among musicians: A factor analysis study. Paper presented at the annual meeting of the American Psychological Association, Washington, DC.

Hafiz, R. (2015). Rethinking Brand Identity to Become an Iconic Brand - A Study on Pepsi. Asian Business Review, 5(3), 97-102.

Hoff, E. \& Tian, C. (2005). Socioeconomic status and cultural influences on language. Journal of communication Disorders, 38, 271-278.

Krannich, C. R. (2004). 101 Secrets of highly effective speakers: controlling fear, commanding attention [Recorded by B. McDonald]. [CD]. New York: Listen \& Live Audio, Inc.

McCannon, M. \& Crews, T. B. 1999. Most common grammatical and punctuation errors made by undergraduates as perceived by business communication professors. The Delta Pi Epsilon Journal41, 179-186.

McCroskey, J. C. (1977). Oral communication apprehension: A summary of recent theory and research. Human Communication Research, 4, 78-96.

McCroskey, J. C. Oral communication apprehension: Reconceptualization and a new look at measurement. Paper presented at the Central Sate Speech Association, Chicago, 1981. Portions also presented at the SCA, Louisville, 1982.

Parvis, L. F. (2001). The importance of communication and public-speaking skills. Journal of Environmental Health, 63, (pp. 44, 35).

Phillips, G. M. (1968). Reticence: Pathology of the normal speaker. Speech Monographs, 35, 39-49.

Raybould, J. \& Sheddy, V. (2005). Are graduates equipped with the right skills in the employability stakes? Industrial and Commercial Training, 37(5), 259-263

Scott, J. C. (2001). Using the process approach to improve scholarly writing.The Delta Pi Epsilon Journal43, 57-66.

Seligman, M. E. Helplessness: On depression, development and death. San Francisco: W.H. Freeman, 1975.

Sheets, B. H. (2004). Effects of English grammar, usage, mechanics, and spelling instruction in college business communication classes. Journal of Business and Public Affairs, (Fall), 31, 48-54.

Strunk, W. \& White, E.B. (1959). The Elements of Style (Macmillan paperback ed.). New York: The Macmillan Company. 